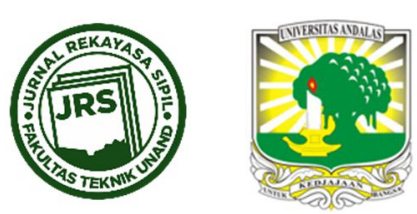

\title{
PERFORMA BETON DENGAN GROUND GRANULATED BLAST FURNACE SLAG TERHADAP SULFATE ATTACK
}

\author{
RIZKI AMALIA TRI CAHYANI ${ }^{*}$, ERNAWAN SETYONO ${ }^{1}$, YUNAN RUSDIANTO ${ }^{1}$ \\ ${ }^{1}$ Jurusan Teknik Sipil, Fakultas Teknik, Universitas Muhammadiyah Malang, Malang \\ "Corresponding Author : $\triangle$ rizkiatcahyani@umm.ac.id
}

Naskah diterima : 6 September 2020. Disetujui: 13 Januari 2021.

\begin{abstract}
ABSTRAK
Serangan sulfat (sulfate attack) termasuk hal yang umum terjadi pada struktur beton, mengingat ion sulfat banyak dijumpai pada tanah, air tanah dan air laut. Peningkatan ketahanan beton melawan sulfat akan berdampak besar pada durabilitas dan umur layan struktur beton. Penambahan supplementary cementitious materials seperti GGBFS (ground granulated blast furnace slag) ke campuran beton telah terbukti memberikan pengaruh positif terhadap durabilitas dan properti mekanis beton. Namun, GGBFS tergolong material yang baru dikembangkan di Indonesia dan potensinya dalam meningkatkan durabilitas beton belum dimanfaatkan secara luas. Berdasarkan hal tersebut, perlu dilakukan investigasi terkait aplikasi GGBFS dan pengaruhnya terhadap durabilitas beton, terutama dalam melawan serangan sulfat. Dalam studi ini, durabilitas beton dengan persentase penggantian GGBFS 30\%, 50\% dan 70\% terhadap total volume binder dievaluasi menggunakan perlakuan siklus basah-kering dalam larutan magnesium sulfat. Tingkat degradasi beton diukur dengan melakukan observasi terhadap perubahan kuat tekan dan massa spesimen akibat serangan sulfat. Hasil penelitian menunjukkan bahwa penggantian GGBFS hingga 50\% dari total volume binder dapat meningkatkan ketahanan beton terhadap serangan sulfat, ditunjukkan dengan kehilangan massa dan reduksi kekuatan yang lebih rendah dibandingkan spesimen kontrol dengan $100 \%$ semen Portland.
\end{abstract}

Kata kunci : durabilitas, GGBFS, kuat tekan, mass loss, sulfate attack

\section{PENDAHULUAN}

Durabilitas beton merupakan aspek yang sangat penting mengingat pengaruhnya yang besar terhadap usia layan struktur beton. Dalam aspek durabilitas, serangan sulfat (sulfate attack) telah menjadi salah satu perhatian utama. Serangan sulfat akan mengakibatkan turunnya kekuatan beton, expansion, spalling permukaan beton dan pada akhirnya berujung pada disintegrasi beton (Bhatty and Taylor, 2006). Struktur beton yang kontak langsung dengan air tanah (groundwater) rentan terhadap serangan sulfat karena air tanah merupakan 
sumber sulfat alami. Sulfat juga umumnya terkandung dalam tanah dan air laut (Vedalakshmi et al., 2005; Whittaker and Black, 2015). Degradasi beton akibat external sulfate attack terdiri dari physical sulfate attack, yaitu pengendapan garam sulfat dalam pori beton, dan chemical sulfate attack, yaitu masuknya ion sulfat ke matriks semen (Whittaker and Black, 2015; Panesar, 2019). Ion sulfat bereaksi dengan kalsium hidroksida dan kalsium aluminat hidrat untuk membentuk gypsum dan ettringite. Gypsum dan ettringite bersifat expansive, sehingga berdampak pada retak, mass loss dan reduksi kekuatan beton (Rozière et al., 2009; Bai, 2016).

Peningkatan ketahanan beton terhadap serangan sulfat dapat ditempuh dengan tiga cara: (a) densifikasi struktur pori yang dapat mereduksi penetrasi ion sulfat; (b) pengurangan $\mathrm{Ca}(\mathrm{OH})_{2}$ (kalsium hidroksida) dalam beton dengan memanfaatkan reaksi pozzolanic; (c) meminimalkan kadar $\mathrm{C}_{3} \mathrm{~A}$ dengan cara mengganti sebagian semen dengan supplementary cementitious materials seperti silica fume, fly ash dan GGBFS (ground granulated blast furnace slag). GGBFS merupakan produk sampingan dari pembuatan besi dan baja. Slag ini memiliki oksida yang sama dengan semen Portland (kapur, silika dan alumina) tapi dengan proporsi yang berbeda. Reaksi pozzolanic dari GGBFS dapat mengurangi sebagian besar $\mathrm{Ca}(\mathrm{OH})_{2}$ yang terbentuk akibat reaksi kimia hidrasi pasta semen (Han et al., 2018). GGBFS akan bereaksi dengan $\mathrm{Ca}(\mathrm{OH})_{2}$ membentuk gel C-S-H sekunder, sehingga secara signifikan meningkatkan ketahanan pasta terhadap serangan kimia (Oner and Akyuz, 2007). Studi terdahulu menunjukkan bahwa penggunaan GGBFS dapat memperbaiki struktur pori dan membuatnya lebih rapat (Attari, McNally and Richardson, 2016). Penelitian lain menyatakan bahwa GGBFS dapat digunakan sebagai pengganti semen hingga 50\% dari total volume binder tanpa adanya reduksi kekuatan tekan beton (Raman and Krishnan, 2017; Cahyani and Rusdianto, 2020).

GGBFS telah digunakan secara luas untuk meningkatkan performa durabilitas beton (Zuquan et al., 2018). Penambahan GGBFS terbukti berdampak positif terhadap ketahanan mortar dan beton melawan serangan sulfat (López, Pineda and Gutiérrez, 2015; Atahan and Arslan, 2016). Namun, GGBFS masih tergolong material baru di Indonesia dan potensinya dalam meningkatkan durabilitas beton belum dimanfaatkan secara luas. Selain itu, GGBFS yang diproduksi di Indonesia belum tentu sama persis dengan produksi negara lain, baik dari segi komposisi kimia maupun teknologi produksi. Melihat hal tersebut, investigasi terkait dengan aplikasi GGBFS yang telah dikembangkan di Indonesia dan pengaruhnya terhadap durabilitas beton penting untuk dilakukan. Studi ini turut mengusulkan batas kadar penggantian GGBFS berdasarkan performa durabilitas beton.

Laju deteriorasi beton dapat meningkat ketika beton berada dalam kondisi siklus basahkering (wetting-drying cycle) (Ming, Deng and Li, 2016; Tian and Han, 2017). Struktur beton pada zona pasang-surut air laut akan mengalami mekanisme ini, yaitu siklus keringnya menyebabkan adanya kristalisasi garam yang mempercepat proses kerusakan beton. Dalam studi ini, evaluasi kerusakan beton yang disebabkan kombinasi serangan sulfat dan aksi siklus basah-kering diukur dengan melihat perubahan kekuatan tekan dan massa spesimen beton. Kemudian dilakukan observasi pengaruh kadar penggantian GGBFS terhadap ketahanan beton melawan serangan sulfat. Studi ini memberikan gambaran performa beton dengan GGBFS yang terpapar lingkungan sulfat. 


\section{METODA PENELITIAN}

\subsection{Material}

Dalam studi ini, kombinasi OPC (Ordinary Cement Portland) dan GGBFS digunakan sebagai binder. GGBFS berasal dari PT. Krakatau Semen Indonesia. Agregat kasar berupa batu pecah dengan diameter 5-30 mm, sedangkan agregat halus menggunakan pasir alami dengan diameter 0-5 $\mathrm{mm}$. Campuran beton dibuat dengan rasio water-to-binder $(\mathrm{w} / \mathrm{b}) 0,45$ dan total volume binder $428 \mathrm{~kg} / \mathrm{m}^{3}$. GGBFS menggantikan semen dengan persentase $30 \%$, $50 \%$ dan $70 \%$ dari total volume binder. Tidak digunakan tambahan chemical admixture dalam campuran beton. Spesimen beton berupa kubus berukuran $100 \times 100 \times 100 \mathrm{~mm}$ dan digunakan untuk mengukur kuat tekan dan perubahan massa spesimen. Semua spesimen dikeluarkan dari cetakannya 24 jam setelah pengecoran, kemudian spesimen dirawat selama 90 hari untuk memastikan kekuatan beton GGBFS telah tercapai dengan penuh. Proporsi material campuran beton dapat dilihat dalam Tabel 1.

Tabel 1. Proporsi Campuran Spesimen Beton

\begin{tabular}{|c|c|c|c|c|c|c|c|}
\hline \multirow{2}{*}{ Spesimen } & \multirow{2}{*}{ GGFBS\% } & \multirow{2}{*}{$\begin{array}{c}\text { Air } \\
\left(\mathrm{kg} / \mathrm{m}^{3}\right)\end{array}$} & \multicolumn{2}{|c|}{$\operatorname{Binder}\left(\mathrm{kg} / \mathrm{m}^{3}\right)$} & \multirow{2}{*}{$\begin{array}{c}\text { Agregat Kasar } \\
\left(\mathrm{kg} / \mathrm{m}^{3}\right)\end{array}$} & \multirow{2}{*}{$\begin{array}{c}\text { Pasir } \\
\left(\mathrm{kg} / \mathrm{m}^{3}\right)\end{array}$} & \multirow{2}{*}{$w / b$} \\
\hline & & & Semen & GGFBS & & & \\
\hline $\mathrm{CN}$ & 0 & 194 & 428 & 0 & 815 & 996 & 0,45 \\
\hline CG30 & 30 & 194 & 300 & 128 & 815 & 996 & 0,45 \\
\hline CG50 & 50 & 194 & 214 & 214 & 815 & 996 & 0,45 \\
\hline CG70 & 70 & 194 & 128 & 300 & 815 & 996 & 0,45 \\
\hline
\end{tabular}

\subsection{Metoda Penelitian}

Dalam penelitian ini, digunakan $10 \%$ larutan $\mathrm{MgSO}_{4}$ (magnesium sulfat) untuk mengevaluasi durabilitas beton. Larutan mengandung 100 gram $\mathrm{MgSO}_{4}$ per satu liter air. Setelah perawatan standar selama 90 hari, spesimen beton direndam larutan sulfat kemudian dikeringkan secara bergantian (siklus basah-kering). Dalam studi ini, sistem siklus basah-kering dibuat berdasarkan prosedur yang digunakan oleh Liang et al. (2018), namun dengan sedikit penyesuaian. Prosedur oleh Liang et.al. terdiri dari perendaman spesimen kubus dalam larutan sulfat selama $16 \mathrm{jam}$, dan pengeringan dalam oven bersuhu $50^{\circ}$ selama 8 jam, sedangkan dalam studi ini, spesimen beton direndam dalam larutan sulfat pada suhu ruang selama 16 jam kemudian dikeringkan di udara selama 32 jam, mengingat waktu kejenuhan akibat perendaman lebih cepat dibandingkan waktu untuk pengeringan. Proses ini diulang selama 35 kali siklus basah-kering. Larutan sulfat diperbarui setiap bulan selama perlakuan berlangsung. Pada tiap siklus, kehilangan dan penambahan massa diukur menggunakan skala elektronik. Perubahan tampak spesimen diobservasi secara visual dan difoto. Pemantauan dilakukan secara berkala untuk memeriksa tanda-tanda deteriorasi seperti edge softening, retak dan spalling.

Kuat tekan (compressive strength) diuji menurut SNI 1974:2011. Kuat tekan yang diambil merupakan hasil rerata dari tiga spesimen untuk setiap variabel yang berbeda. Setelah dirawat selama 90 hari, kuat tekan kubus beton diuji terlebih dahulu untuk menentukan nilai awal kuat tekan sebelum spesimen terpapar serangan sulfat. Setelah 7 dan 21 siklus basah-kering, kubus beton kembali diuji untuk mengukur perubahan nilai kuat tekan akibat kombinasi perlakukan siklus basah-kering dan serangan sulfat. Perbandingan antara kuat tekan awal dengan kuat tekan yang diukur pada siklus basah-kering yang berbeda kemudian 
dinyatakan sebagai reduksi kuat tekan (compressive strength reduction) dan dihitung dengan persamaan:

$$
\text { Reduksi kuat tekan }(\%)=\frac{X-Y}{X}
$$

Dengan $X$ adalah kuat tekan rerata spesimen setelah perawatan 90 hari dan $Y$ adalah kuat tekan rerata spesimen setelah dikenai kombinasi siklus basah-kering dan serangan sulfat.

\section{HASIL DAN PEMBAHASAN}

\subsection{Observasi Visual}

Umumnya, proses kerusakan material berbahan dasar semen (cement-based) yang terpapar serangan sulfat memiliki tanda-tanda yang terlihat secara visual. Contohnya adalah retak atau spalling beton akibat kristalisasi garam dan presipitasi gypsum dan ettringite. Tian dan Han (2017) mengamati tanda deteriorasi beton yang dikenai kombinasi aksi siklus basahkering dengan larutan sodium sulfat. Selama proses deteriorasi, produk expansive dari laruran sulfat mengisi pori beton, menyebabkan adanya retak yang mulai menyebar dari pori-pori beton. Spesimen juga menunjukkan sanding phenomena di tepi dan sudut kubus beton.

Namun, dalam penelitian ini, semua spesimen tidak menunjukkan tanda-tanda deteriorasi beton yang dapat terlihat secara visual hingga akhir perlakuan 35 siklus basah-kering, Gambar 1 dan Gambar 2 menunjukkan spesimen dengan persentase GGBFS yang bervariasi yang terpapar larutan magnesium sulfat selama 7 dan 35 siklus basah-kering. Pemeriksaan pada permukaan, tepi dan sudut kubus beton tidak menunjukkan adanya retakan maupun softening (ujung dan tepi beton mulai terkikis) yang dapat dilihat secara visual. Tidak ditemui perubahan fisik dan spesimen tetap utuh seperti saat awal pengujian. Namun, ditemukan pasir yang mengendap di dasar wadah yang digunakan untuk merendam spesimen. Pasir ini diduga berasal dari sanding phenomena, yaitu spesimen beton terkikis sedikit demi sedikit akibat serangan sulfat. Temuan ini sesuai dengan fenomena hilangnya massa beton seiring waktu yang terjadi selama perlakuan siklus basah-kering. Ada kemungkinan bahwa sebenarnya tepi dan ujung spesimen mulai terkikis, namun perubahannya terlalu kecil untuk dapat diamati secara visual. Perpanjangan waktu paparan sulfat dipercaya akan menimbulkan kerusakan fisik yang lebih terlihat (Allahvedi and Hashemi, 2015).

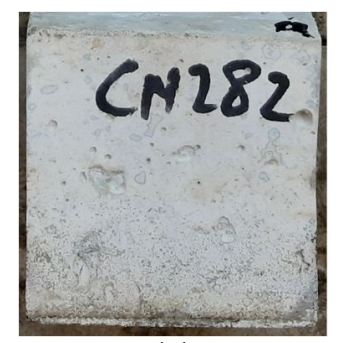

(a)

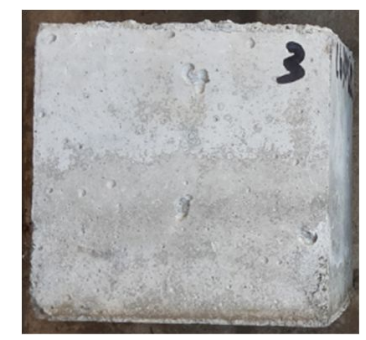

(b)

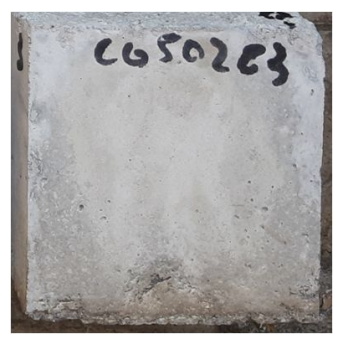

(c)

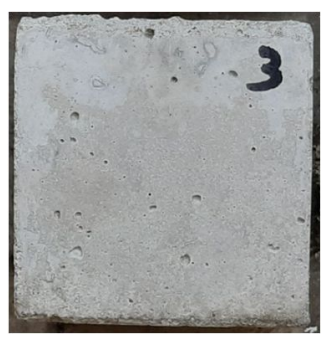

(d)

Gambar 1. Kubus beton setelah terpapar serangan sulfat selama 7 siklus basah-kering: (a) Spesimen CN (100\% OPC); (b) Spesimen CG30 (30\% GGBS); (c) Spesimen CG50 (50\% GGBS); (d) Specimen CG70 (70\% GGBFS) 


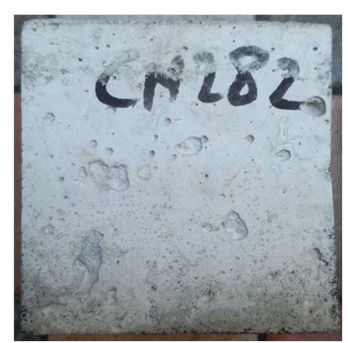

(a)

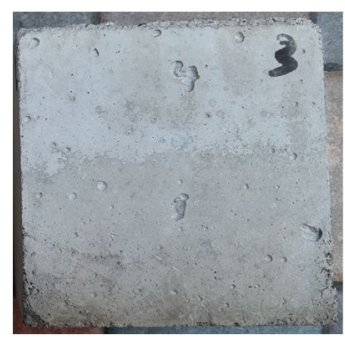

(b)

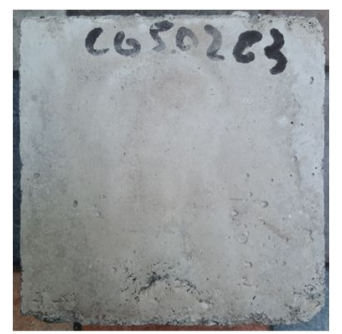

(c)

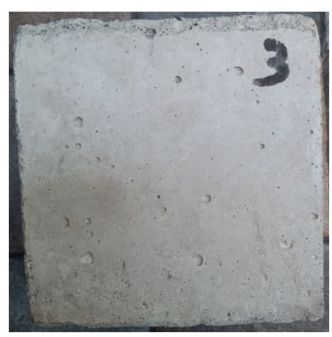

(d)

Gambar 2. Kubus beton setelah terpapar serangan sulfat selama 35 siklus basah-kering: (a) Spesimen CN (100\% OPC); (b) Spesimen CG30 (30\% GGBS); (c) Spesimen CG50 (50\% GGBS); (d) Specimen CG70 (70\% GGBFS)

\subsection{Kehilangan Massa (Mass Loss)}

Penambahan dan kehilangan massa spesimen akibat aksi siklus basah-kering dengan larutan magnesium sulfat ditunjukkan pada Gambar 3. Seperti terlihat di gambar tersebut, semua spesimen mengalami dua fase perubahan massa yang berbeda selama proses deteriorasi beton. Pada fase pertama, saat spesimen baru terpapar serangan sulfat, spesimen mengalami peningkatan massa. Penambahan massa pada spesimen disebabkan reaksi antara larutan sulfat dengan produk hidrasi semen yang mengisi pori beton. Terjadinya pengendapan garam sulfat pada pori beton saat siklus pengeringan juga berperan dalam peningkatan massa spesimen. Pada fase kedua, ion-ion sulfat mulai menghancurkan ikatan C-S-H dalam matriks beton. Spesimen berangsur-angsur terkikis, mengakibatkan massa spesimen terus menurun hingga akhir pengujian.

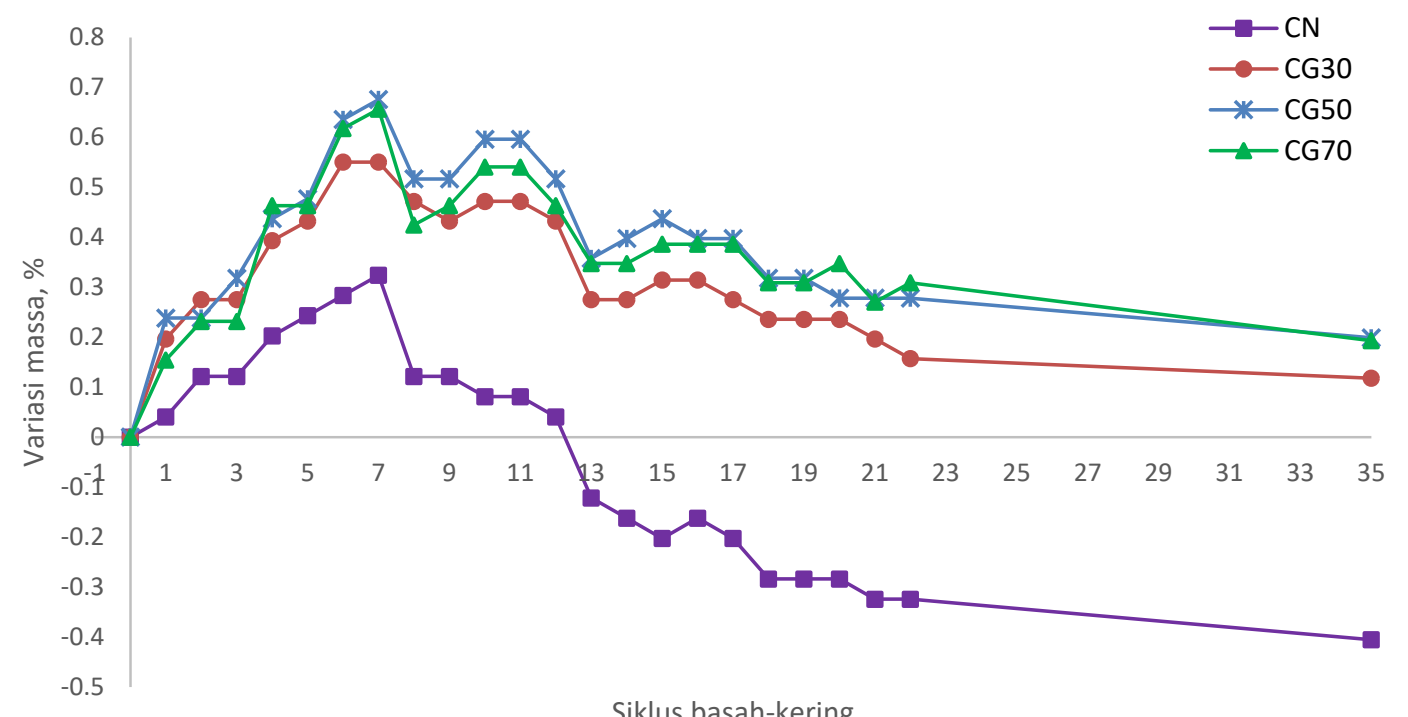

Gambar 3. Variasi massa spesimen akibat kombinasi serangan magnesium sulfat dan perlakuan basah-kering

Spesimen dengan GGBFS menunjukkan penambahan massa awal yang lebih tinggi dibandingkan spesimen dengan $100 \%$ OPC. Pada 7 siklus basah-kering, massa kubus beton 
GGBFS bertambah sekitar 0,7\%, sedangkan penambahan massa kubus beton OPC sekitar $0,3 \%$. Setelah melewati 7 siklus basah-kering, massa spesimen mulai berkurang. Pada akhir 35 siklus basah-kering, hanya variasi massa spesimen OPC yang bernilai negatif, menunjukkan kehilangan material paling besar dialami spesimen tanpa GGBFS. Kehilangan material dapat diakibatkan oleh pengikisan beton atau mungkin juga diakibatkan oleh pitting deterioration. Berdasarkan grafik variasi massa (Gambar 3), sekilas terlihat bahwa semakin tinggi level penggantian GGBFS maka semakin meningkat ketahanan spesimen terhadap serangan sulfat, karena spesimen dengan persentase GGBFS 50\% dan 70\% mengalami kehilangan massa yang paling rendah. Namun, analisis data kekuatan tekan menunjukkan kesimpulan yang berbeda. Hal ini terlihat jelas dari grafik reduksi kekuatan (Gambar 5).

\subsection{Kuat Tekan}

Dalam studi ini, kekuatan tekan spesimen diukur setelah 7 dan 21 siklus basah-kering, kemudian dibandingkan dengan kekuatan tekan sebelum spesimen terpapar serangan sulfat. Seperti ditunjukkan pada Gambar 4, kuat tekan spesimen dengan kadar penggantian GGBFS 0\%, 30\% dan 50\% mengalami peningkatan setelah 7 perlakuan siklus basah-kering. Peningkatan kuat tekan ini tidak hanya disebabkan progress proses hidrasi di dalam spesimen (Allahvedi and Hashemi, 2015), namun dapat dikaitkan pula dengan peningkatan kepadatan (density) spesimen akibat adanya kristal sulfat dan hydration expansive products (gypsum, ettringite) yang mengisi pori beton (Allahvedi and Hashemi, 2015; Tian and Han, 2017).

Reduksi kekuatan terjadi saat spesimen terpapar lingkungan sulfat dalam waktu yang panjang. Pada 21 siklus basah-kering, reduksi kekuatan spesimen dengan GGBFS 0\%, 30\% dan $50 \%$ masing-masing adalah $16 \%, 10 \%$ dan $8 \%$. Temuan ini disajikan secara grafis dalam Gambar 5. Dalam gambar tersebut, kuat tekan pada siklus basah-kering yang berbeda dibandingkan dengan nilai kuat tekan awal spesimen setelah 90 hari perawatan standar. Dapat disimpulkan bahwa ketiga jenis spesimen (0\%, 30\% dan 50\% GGBFS) memiliki risiko deteriorasi ketika terpapar serangan sulfat. Namun, spesimen GGBFS memperlihatkan ketahanan yang lebih baik dibandingkan spesimen OPC, ditunjukkan dengan reduksi kekuatan yang lebih rendah.

Reduksi kekuatan yang terjadi diyakini akibat dua mekanisme deteriorasi. Pertama, hydration expansion product dan kristal sulfat mulai menekan pori, menyebabkan ekspansi beton dan microcracking. Kedua, serangan sulfat menyebabkan dekalsifikasi C-S-H akibat terjadinya leaching senyawa kalsium (Whittaker and Black, 2015; Panesar, 2019). C-S-H mulai hancur dan kehilangan kemampuannya sebagai pengikat, yang berujung pada pengikisan spesimen (sanding phenomena). Hasil yang didapat sesuai dengan pengujian kehilangan massa, bahwa massa spesimen berkurang setelah melewati 7 siklus basah-kering. Penting untuk dicatat bahwa mekanisme deteriorasi pasta berbahan dasar GGBFS akibat serangan sulfat dapat berbeda dengan pasta berbahan dasar OPC. Penelitian oleh O'Connell, McNally dan Richardson (2012) dan Allahvedi dan Hashemi (2015) menyatakan bahwa produk expansive pasta dengan GGBFS yang terpapar serangan sulfat sebagian besar didominasi oleh pembentukan gypsum. Hampir tidak ada atau sangat sedikit ettringiteyang terbentuk. Hal ini akibat adanya reduksi kandungan $\mathrm{C}_{3} \mathrm{~A}$ yang bereaksi dengan ion sulfat.

Spesimen dengan 70\% GGBFS memperlihatkan perilaku yang berbeda. Seperti terlihat pada Gambar 4 dan Gambar 5, kekuatan tekan spesimen terus menurun pada 7 dan 21 siklus pengeringan dan perendaman dalam larutan magnesium sulfat. Spesimen dengan $70 \%$ GGBFS juga mengalami reduksi kuat tekan paling tinggi, mencapai $28 \%$ di siklus ke-21. 
Tren kekuatan yang terus menurun menunjukkan proses hidrasi terhenti dengan paksa dan deteriorasi telah terjadi sejak awal spesimen terpapar lingkungan sulfat. Dapat disimpulkan bahwa setelah melewati batas tertentu, penambahan GGBFS tidak meningkatkan ketahanan beton melawan serangan sulfat. Fenomena ini dapat dijelaskan dengan adanya GGBFS yang tidak bereaksi seiring peningkatan persentase penggantian GGBFS. GGBFS yang tidak terikut dalam reaksi pozzolanic, berperan seperti material pengisi (filler) dalam pasta (Oner and Akyuz, 2007).

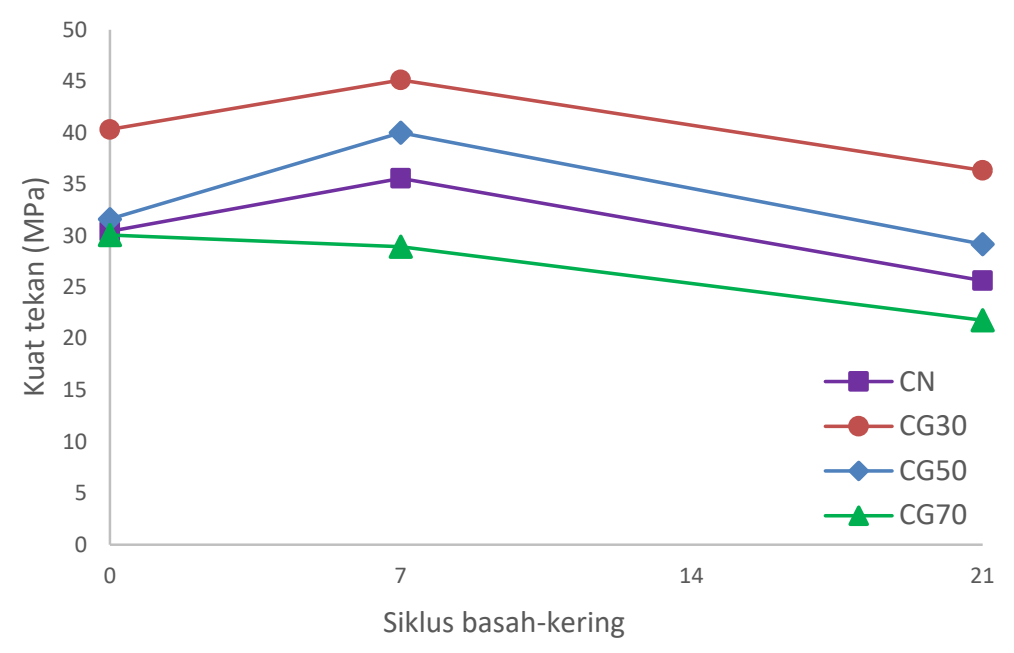

Gambar 4. Kuat tekan spesimen akibat kombinasi serangan magnesium sulfat dan perlakuan basah-kering

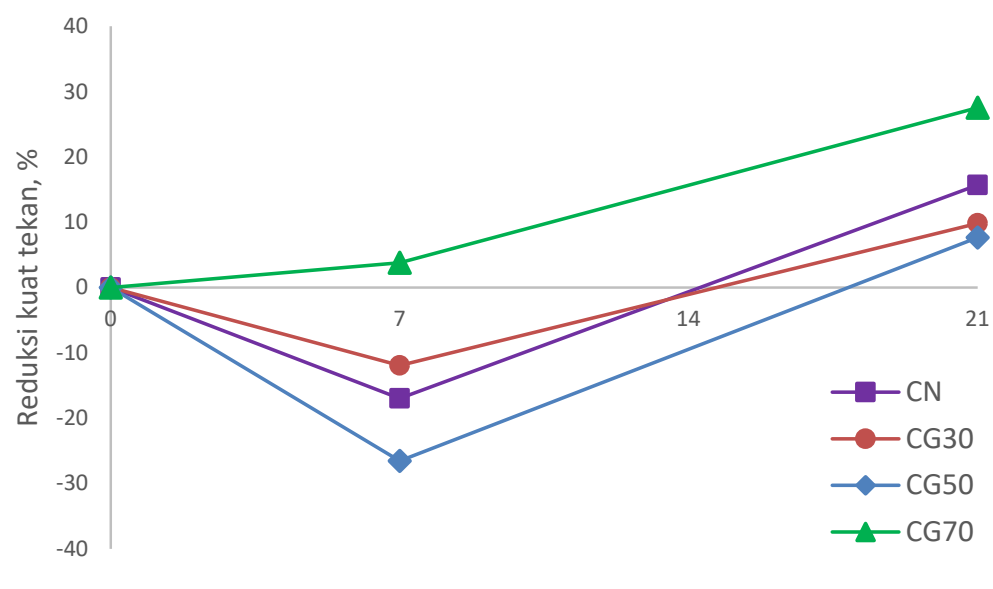

Siklus basah-kering

Gambar 5. Reduksi kuat tekan spesimen akibat kombinasi serangan magnesium sulfat dan perlakuan basah-kering 


\section{KESIMPULAN}

Studi ini mempelajari kerusakan beton GGBFS akibat kombinasi aksi siklus basah-kering dengan larutan magnesium sulfat. Ketahanan beton GGBFS melawan serangan sulfat dievaluasi dengan mengukur perubahan kuat tekan dan perubahan massa spesimen kubus beton. Berdasarkan hasil penelitian, dapat disimpulkan bahwa penggunaan GGBFS dapat meningkatkan ketahanan beton melawan sulfat hingga batas tertentu. Aplikasi GGBFS di atas $50 \%$ dari total volume binder mungkin tidak efisien mengingat semakin tinggi persentase penggantian GGBFS, akan ada porsi GGBFS yang tidak dapat masuk ke reaksi pozzolanic yang justru berperilaku sebagai bahan pengisi. Mekanisme kerusakan beton GGBFS akibat serangan sulfat dapat lebih terlihat dengan memperpanjang waktu paparan lingkungan sulfat.

\section{UCAPAN TERIMA KASIH}

Penulis mengucapkan terima kasih atas dukungan finansial yang diberikan oleh Universitas Muhammadiyah Malang. Ucapan terima kasih juga ditujukan kepada PT. Krakatau Semen Indonesia atas bantuannya dalam menyediakan material GGBFS.

\section{DAFTAR PUSTAKA}

Allahvedi, A. and Hashemi, H. (2015) 'Investigating the resistance of alkali-activated slag mortar exposed to magnesium sulfate attack', International Journal of Civil Engineering, 13(4A), pp. 379-387. doi: 10.22068/IJCE.13.4.379.

Atahan, H. N. and Arslan, K. M. (2016) 'Improved durability of cement mortars exposed to external sulfate attack: The role of nano \& micro additives', Sustainable Cities and Society, 22, pp. 4048. doi: 10.1016/j.scs.2016.01.008.

Attari, A., McNally, C. and Richardson, M. G. (2016) 'A combined SEM - Calorimetric approach for assessing hydration and porosity development in GGBS concrete', Cement and Concrete Composites, 68, pp. 46-56. doi: 10.1016/j.cemconcomp.2016.02.001.

Bai, J. (2016) 'Durability of sustainable construction materials', in Sustainability of Construction Materials. Elsevier, pp. 397-414. doi: 10.1016/B978-0-08-100370-1.00016-0.

Bhatty, J. I. and Taylor, P. C. (2006) 'Sulfate Resistance of Concrete Using Blended Cements or Supplementary Cementitious Materials', Portland Cement Association, (2916), pp. 1-21.

Cahyani, R. A. T. and Rusdianto, Y. (2020) 'Concrete Performance with Ground Granulated Blast Furnace Slag as Supplementary Cementitious Materials', IOP Conference Series: Materials Science and Engineering, 771(1). doi: 10.1088/1757-899X/771/1/012062.

Han, C. et al. (2018) 'Behavior of high performance concrete pastes with different mineral admixtures in simulated seawater environment', Construction and Building Materials, 187, pp. 426-438. doi: 10.1016/j.conbuildmat.2018.07.196.

Liang, C. et al. (2018) 'Prediction of Compressive Strength of Concrete in Wet-Dry Environment by BP Artificial Neural Networks', Advances in Materials Science and Engineering, 2018. doi: 10.1155/2018/6204942.

López, M. M., Pineda, Y. and Gutiérrez, O. (2015) 'Evaluation of Durability and Mechanical Properties of the Cement Mortar Added with Slag Blast Furnace', Procedia Materials Science, 9, pp. 367-376. doi: 10.1016/j.mspro.2015.05.006.

Ming, F., Deng, Y. S. and Li, D. Q. (2016) 'Mechanical and Durability Evaluation of Concrete with Sulfate Solution Corrosion', Advances in Materials Science and Engineering, 2016. doi: 10.1155/2016/6523878.

O’Connell, M., McNally, C. and Richardson, M. G. (2012) 'Performance of concrete incorporating GGBS in aggressive wastewater environments', Construction and Building Materials, 27(1), pp. 368-374. doi: 10.1016/j.conbuildmat.2011.07.036. 
Oner, A. and Akyuz, S. (2007) 'An experimental study on optimum usage of GGBS for the compressive strength of concrete', Cement and Concrete Composites, 29(6), pp. 505-514. doi: 10.1016/j.cemconcomp.2007.01.001.

Panesar, D. K. (2019) 'Supplementary cementing materials', in Developments in the Formulation and Reinforcement of Concrete. Elsevier, pp. 55-85. doi: 10.1016/B978-0-08-102616-8.000034.

Raman, J. V. M. and Krishnan, V. M. (2017) 'Partial Replacement of Cement with GGBS in Self Compacting Concrete for Sustainable Construction', International Journal of Civil Engineering, 4(3), pp. 24-28. doi: 10.14445/23488352/ijce-v4i3p106.

Rozière, E. et al. (2009) 'Durability of concrete exposed to leaching and external sulphate attacks', Cement and Concrete Research, 39(12), pp. 1188-1198. doi: 10.1016/j.cemconres.2009.07.021.

Tian, W. and Han, N. (2017) 'Experiment Analysis of Concrete's Mechanical Property Deterioration Suffered Sulfate Attack and Drying-Wetting Cycles', Advances in Materials Science and Engineering, 2017. doi: 10.1155/2017/5673985.

Vedalakshmi, R. et al. (2005) 'Effect of magnesium and sulphate ions on the sulphate resistance of blended cements in low- and medium-strength concretes', Advances in Cement Research, 17(2), pp. 47-55. doi: 10.1680/adcr.2005.17.2.47.

Whittaker, M. and Black, L. (2015) 'Current knowledge of external sulfate attack', Advances in Cement Research, 27(9), pp. 532-545. doi: 10.1680/adcr.14.00089.

Zuquan, J. et al. (2018) 'Chloride ions transportation behavior and binding capacity of concrete exposed to different marine corrosion zones', Construction and Building Materials, 177, pp. 170-183. doi: 10.1016/j.conbuildmat.2018.05.120. 